\title{
Pobreza franciscana y economía monástica: Prácticas cotidianas de frailes y monjas en Santiago de Chile (1790-1820**
}

\author{
Franciscan Poverty and Monastic Economy: Daily practices \\ of friars and nuns in Santiago de Chile (1790-1820)
}

\author{
Cristián LEAL PINO \\ Universidad del Bío-Bío, Chile \\ https://orcid.org/000o-0002-3797-4656 \\ cleal@ubiobio.cl
}

\author{
Alexandrine DE LA TAILLE-TRÉTINVILLE \\ Universidad de los Andes, Chile \\ https://orcid.org/0000-0002-6919-1138 \\ adelataille@uandes.cl
}

\section{Alejandra FUENTES GONZÁLEZ \\ Universidad de los Andes, Chile \\ https://orcid.org/0000-0001-9843-5392 \\ fuentesgonzalezalejandra@gmail.com}

\begin{abstract}
This article deals with the daily practices of friars and nuns in Santiago, Chile, during the transition from the 18th to the 19th century. Specifically, it compares the observance of the vow of poverty according to the spirituality of the saints of Assisi: Saint Francis and Saint Clare. Through the compilation, analysis and interpretation of conventual sources, we can establish that it was precisely the rule itself and its mitigation that allowed the «excesses» that separated the sisters from the founder's ideal, whereas the legislative texts for the Friars Minor meant that they did not undergo significant changes in this aspect. Other factors were the impossibility of going into the world to obtain alms, and the consequent requirement of a dowry.
\end{abstract}

Keywords: Poor Clares; Franciscans; Santiago, Chile; Poverty; Rule.
Resumen: El presente artículo aborda las prácticas cotidianas de frailes y monjas en Santiago de Chile, durante el tránsito del siglo XVIII al XIX. Específicamente compara la observancia del voto de pobreza según la espiritualidad de los santos de Asís: San Francisco y Santa Clara. A la luz del registro, análisis e interpretación de fuentes conventuales; se plantea que fue precisamente la misma regla y su mitigación la que permitió los «excesos» que apartaron a las religiosas del ideal de la fundadora, a diferencia de los textos legislativos para los Hermanos Menores, que no sufrieron cambios significativos en este aspecto. Otros factores fueron la imposibilidad de salir al mundo tras la limosna y el consecuente requisito de la dote.

Palabras clave: Clarisas; Franciscanos; Santiago de Chile; Pobreza; Regla.

* Este artículo es resultado de la investigación realizada en el marco del Proyecto Fondecyt iniciación n. ${ }^{\circ} 11160795$, denominado: «Vida conventual y formas de financiamiento en una Orden mendicante en Chile: Los franciscanos en el tránsito de la Colonia a la República», y del trabajo conjunto entre historiadores del Instituto de Historia de la Universidad de los Andes, Santiago de Chile y el Departamento de Ciencias Sociales de la Universidad del Bío-Bío, Chillán, Chile. 


\section{INTRODUCCIÓN}

La presencia de la Orden Franciscana en Chile data de 1553. Los frailes llegaron desde Perú y se establecieron en la Cañada de Santiago. Su carisma, según la impronta del fundador, requería de la absoluta pobreza para transmitir el mensaje evangélico hasta los más recónditos lugares. Esta labor apostólica se complementó en el Reino con el establecimiento de una rama femenina el año 1567 en la ciudad de Osorno, las «Isabelas», quienes profesaron la Regla de Urbano IV (1263) una vez asentadas en Santiago, a principios del siglo XVII. Dicha normativa introdujo la clausura, el requisito de la dote y la posesión de propiedades por parte de la comunidad para garantizar el cuidado de la salud de las monjas, los gastos del culto, la atención pastoral de la comunidad y el mantenimiento del edificio conventual.. Siguiendo los postulados de la Reforma Católica que revitalizaban las bases de la doctrina de la Iglesia, era necesario que la labor del clero se complementara con la de las mujeres consagradas, siendo los clásicos modelos de la época, San Ignacio de Loyola y Teresa de Jesús, quienes personificaban la entrega en el claustro y la misión.

En el caso de los franciscanos, si bien la Regla encarna los arquetipos medievales de Francisco y Clara de Asís, el paso del tiempo mitigó las prácticas de hombres y mujeres en diversos aspectos. En este artículo proponemos revisar a través de un estudio comparativo, la observancia en Chile del voto de pobreza, tan representativo de su espiritualidad para hombres y mujeres. Para ello, se abordan las últimas décadas del siglo XVIII y los comienzos del siglo XIX, a través de fuentes conventuales, en su mayoría inéditas. El periodo presenta especial interés dado el contexto de las reformas borbónicas a fines de siglo y el proceso de independencia en el siguiente.

La pregunta por la austeridad se analiza a través de los documentos relativos a ingresos y gastos de ambos monasterios en el marco temporal señalado. Fuentes como libros de cuentas, censos, capellanías, disposiciones y visitas pastorales son clave para comprender el problema. Asimismo, la Regla de San Francisco y la propia de las clarisas permiten confrontar las prácticas de los franciscanos chilenos con el espíritu de la Orden en cuanto al cumplimiento de dicho referente.

A la luz de los archivos monásticos, se propone entonces que los frailes siguieron con mayor autenticidad la austeridad seráfica que las religiosas. Estas últimas, blanco de amonestaciones por parte de la autoridad civil y eclesiástica, reflejan la mitigación femenina de la Regla que fue común en América Latina como lo ha señalado la historiografía reciente. 


\section{HISTORIOGRAFÍA Y ECONOMÍA MONÁSTICA EN HISPANOAMÉRICA}

Durante las últimas décadas, la historiografía ha demostrado un creciente interés en los temas vinculados a las órdenes religiosas en Hispanoamérica. Sus orígenes, prácticas, intelectualidad y múltiples aspectos han concentrado la atención de los estudiosos. En cuanto al tema económico, fundamental en nuestro estudio, son los trabajos de David Brading ${ }^{1}$, Asunción Lavrin ${ }^{2}$ y Gisela von Wobe$\operatorname{ser}^{3}$ para el caso novohispano. El primero, en su estudio sobre el clero mexicano y el movimiento insurgente de 1810, como en el del obispado de Michoacán hacia el mismo año, repara en las fuentes de los ingresos eclesiásticos del clero secular, como también analiza en sus escritos las «conductas, pensamientos e ideas de la sociedad mexicana vinculando economía, política y religión $\gg^{4}$. Asunción Lavrin, en sus estudios sobre los conventos de monjas y las cofradías, entra de lleno al tema de la «economía espiritual» y la «economía material», aspecto central de esta investigación. Las instituciones sociales, como las parroquias, las órdenes religiosas, las cofradías, giran en torno a una doble hélice, «sus fines éticos o espirituales y los medios materiales de que depende su existencia ${ }^{5}$. Por su parte, Gisela von Wobeser, junto con analizar el crédito eclesiástico y las capellanías de misas, se detiene en el tema de la consolidación de los vales reales en las diócesis, parroquias y conventos (femeninos y masculinos), llevada a cabo en primer término por Carlos III, y luego profundizada por Carlos IV. Su finalidad era superar el déficit económico ocasionado por las sucesivas guerras europeas. El listado de conventos afectados, incluyendo el franciscano, es muestra de lo que significó el poder de los reyes borbónicos en el contexto de la Nueva España.

1 David BRADING, El clero mexicano y el movimiento insurgente de 1810, en Revista Relaciones, 5 (invierno 1981), pp. 5-26.

2 Asunción LAVRIN, Cofradías novohispanas: economías material y espiritual, en María MARTíNEZ, Gisela VON WOBESER, Juan MUÑOZ (coords.), Cofradías, capellanías y obras pías en la América colonial (Serie Historia Novohispana, 61), Universidad Nacional Autónoma de México, México, 1998, pp. 49-64.

3 Gisela VON WOBESER, El Crédito Eclesiástico en la Nueva España, siglo XVIII, Universidad Autónoma de México, México, 1994; Dominación Colonial. La consolidación de vales reales, 1804-1812, México, 2003; Vida eterna y preocupaciones terrenales. Las capellanías de misas en la Nueva España, 1700-1821, México, 1999.

4 Alejandra GuERra, Devociones y devotos en Santiago de Chile (1760-1800), Consideraciones en torno al estudio de las realidades materiales e inmateriales de las prácticas religiosas tardo-coloniales, en Eduardo CAVIERES y Juan CÁCERES (eds.), Lecturas y (RE) lecturas en historia colonial, Valparaíso, p. 128.

5 Asunción LAVRIN, Cofradías novohispanas: economías material y espiritual, en María MARTÍNEZ, Gisela VON WOBESER, Juan MUÑOZ (coords.), Cofradías, capellanías y obras pías en la América colonial... [ver n. 3], p. 49. 
En Argentina, destacan los aportes de Roberto Di Stefano y Loris Zanata ${ }^{6}$, quienes se preguntan si el dinero que prestaban los conventos, que para algunos era «el banco de América colonial», favorecía o perjudicaba a la economía americana. De igual modo, reparan en los bienes capellánicos, esto es, las rentas de la masa de bienes sobre las que se fundaban las capellanías, con la finalidad de sostener un capellán a lo largo del tiempo, que se comprometía a celebrar las misas estipuladas por el fundador de la capellanía a favor de los difuntos designados por el mismo ${ }^{7}$. Carlos Mayo y Jaime Peire postulan que para el caso del clero regular de Buenos Aires, los préstamos les permitían financiar a largo plazo sus propias actividades ${ }^{8}$. Jorge Troisi ${ }^{9}$, plantea que las llamadas Reformas Borbónicas afectaron negativamente a las religiones, por ejemplo, el subsidio eclesiástico del año 1790 para todo el clero latinoamericano, «gravándolo con un sexto de sus estipendios con el fin de apoyar económicamente en un eventual conflicto europeo» ${ }^{10}$. $\mathrm{Al}$ respecto, es relevante también la investigación de Alicia Fraschina, quien analiza los efectos de tales reformas en los conventos de monjas de Buenos Aires, a fines del siglo XVIII y comienzos del siglo XIX ${ }^{11}$.

Para Chile, si bien existe bibliografía general y específica para los franciscanos y las clarisas; aún no se ha llevado a cabo un estudio que las compare bajo la pregunta de la observancia del voto de pobreza. Son iluminadores los trabajos de Gabriel Guarda Geywitz, especialmente La Edad Media en Chile, donde sugiere que las órdenes mendicantes incursionaron en «actividades lucrativas reñidas con las reglas de sus institutos» ${ }^{12}$. Desde una perspectiva general, abordan la dimen-

6 Roberto Di Stefano-Loris ZanatTa, Historia de la Iglesia Argentina, Buenos Aires, 2009; Roberto Di STEFANO, El púlpito y la plaza. Clero, sociedad y política de la monarquía católica a la república rosista, Buenos Aires, 2004.

7 Roberto Di STEFAnO y Loris ZanATTA, Historia de la Iglesia Argentina... [ver n. 7], p. 75.

8 Carlos MAYO, Jaime PEIRE, Iglesia y crédito colonial: La política crediticia de los conventos de Buenos Aires (1767-1810), en Revista de Historia de América, 12 (1991), p. 75.

9 Jorge Troisi MELEAN, Socios incómodos. Los franciscanos de Córdoba en una era de transformaciones (1767-1829), Rosario, 2016; Los franciscanos de la Provincia de Asunción en la transición del periodo borbónico y de las primeras décadas independientes, en Gardenia VIDAL y Pablo VAGLIENTE (comps.), Por la señal de la cruz. Estudios sobre la Iglesia Católica y sociedad en Córdoba, s. XVIII-XIX, Córdoba, 2006, pp. 115-132.

10 Jorge Troisi Melean, Los franciscanos de la Provincia de Asunción... [ver n. 10], p. 123.

11 Alicia FrasCHINA, Ilustración y modernidad en los conventos de monjas de Buenos Aires: 1754-1833. Reformas y continuidades, Lucr ENRIQUEZ, Rodolfo AGUIRRE, Francisco CERVANTES (coord.), Ciudad de Buenos Aires, a fines del siglo XVIII y comienzos del siglo en Hispania Sacra, LX/122 (2008), pp. 445-466.

12 Gabriel Guarda, La Edad Media de Chile. Historia de la Iglesia desde la fundación de Santiago a la incorporación de Chiloé, 1541-1826, Santiago de Chile, 2011, p. 483. 
sión masculina y femenina de la vida consagrada en Chile durante la Colonia, René Millar y Carmen Duhart, aludiendo específicamente al convento de la Alameda ${ }^{13}$. La publicación llevada a cabo con ocasión de los 450 años de la Orden en Chile ofrece un completo panorama bajo diferentes miradas específicas sobre la historia de la rama masculina, aunque también incluye un estudio sobre las capuchinas $^{14}$.

En cuanto a lo económico destacan las investigaciones realizadas por María Eugenia Horvitz acerca de las capellanías de misas, por ejemplo, en su última publicación titulada Memoria del nombre y salvación eterna. Los notables y las capellanías de misas en Chile (1557-1930) ${ }^{15}$. Junto con ello, es relevante el artículo de Marcial Sánchez Gaete titulado «La capellanía, camino de salvación», el que analiza su funcionamiento, los actores que intervienen en ella y su relación con la vida cotidiana, para luego ejemplificar con algunos casos del monasterio de las clarisas ${ }^{16}$. Las capellanías también han sido estudiadas por Juan Guillermo Muñoz en conventos franciscanos y mercedarios de Colchagua, en sus artículos: «Las estrategias de una elite frente a la tierra y al cielo: capellanías en Colchagua en el siglo XVII» $\mathrm{y}$ «Convento de San Antonio de la doctrina de Malloa. Síndicos y benefactores (siglo XVII y XVIII) ${ }^{17}$. Todos estos trabajos monográficos han sido sugerentes para esta investigación, pero no comparan puntualmente las ramas femenina y masculina de la Orden.

La mercedaria Imelda Cano Roldán -referente indiscutido para el estudio histórico de las mujeres en Chile-, aunque no se refiere al tema económico, es importante porque trabaja las fuentes del archivo de las clarisas ${ }^{18}$. En la misma

13 René MILlaR y Carmen DUHART, La vida en los claustros: Monjas y frailes, disciplinas y devociones, en Cristián GAZMURI y Rafael SAGREDO (eds.) Historia de la vida privada en Chile. El Chile tradicional de la conquista a 1840, Santiago de Chile, 2007, pp. 125-159.

14 René Millar y Horacio ARÁNgUIZ Donoso (eds.), Los franciscanos en Chile: Una bistoria de 450 años, Santiago de Chile, 2005.

15 María Eugenia HoRvitz, Memoria del nombre y salvación eterna. Los notables y las capellanías de misas en Chile (1557-1930), Santiago de Chile, 2006.

16 Marcial Sanchez Gaete, La Capellanía camino de salvación, en Anuario de Historia de la Iglesia en Chile, 18 (2000), pp. 9-11.

17 Juan Guillermo MUÑOZ, Las estrategias de una elite frente a la tierra y al cielo: capellanías en Colchagua en el siglo XVII, en María MARTÍNEZ, Gisela VON WOBESER, Juan MUÑOZ (coords.), Cofradías, capellanías y obras pías en la América colonial... [ver n. 3], pp. 155-172; Juan Guillermo MUÑOZ, El convento de San Antonio en la doctrina de Malloa: Síndicos y Benefactores, siglo XVII y XVIII, en René MILlaR y Horacio ARÁNGUIZ DONOSO (eds.), Los Franciscanos en Chile... [ver n. 14], pp. 69-102.

18 Imelda CANO, Las mujeres en el Reyno de Chile, Santiago de Chile, 1981. 
línea, Armado de Ramón y José Manuel Larraín, al emprender el estudio de los orígenes de la vida económica en Chile, se basan en gran medida en las fuentes clarisas y de otros monasterios para abordar el problema ${ }^{19}$.

\section{EL VALOR DE LAS FUENTES CONVENTUALES}

La aproximación a la observancia del voto de pobreza en los monasterios de la Cañada se sustenta en el trabajo con fuentes directas disponibles en sus archivos históricos, cuyos recientes procesos de sistematización han permitido su acceso y estudio ${ }^{20}$.

Respecto a las fuentes consultadas para el análisis de los franciscanos, se revisó documentación manuscrita e impresa existente en el archivo Histórico Franciscano Fr. Rigoberto Iturriaga Carrasco y la Biblioteca de la Recoleta Franciscana de Santiago de Chile. Específicamente se compulsó la información sobre las cuentas del convento de la Alameda y de la Recoleta contenidas en las disposiciones, las cuales eran presentadas por los padres guardianes de los conventos trienalmente en los Capítulos Provinciales; el Catecismo Seráfico (Breve exposición de la Regla de la Orden de los Frailes Menores), Constituciones Municipales, Memorias de frailes y los Estatutos Generales de Barcelona de 1621.

En el caso del Archivo del Monasterio de Santa Clara de Antigua Fundación, para esta investigación han sido fundamentales los libros de ingresos y egresos efectuados en el monasterio; censos, referidos a información sobre censuarios, monto de los principales y los réditos, pagos y deudas, escrituras de imposición, documentos de sucesión de tierras, causas ejecutivas, solicitudes de embargo, remates, tasaciones, entre otros; y capellanías fundadas a favor del monasterio,

19 Armando de RAMÓn y José LARRAín, Una metrología colonial para Santiago de Chile: De la medida castellana al sistema métrico decimal, en Revista Historia, 14 (1979), pp. 5-69; Armando de RAMÓN y José LARRAín, Orígenes de la vida económica chilena: 1659-1808, Santiago de Chile, 1981.

20 La labor de catalogación, transcripción y publicación de una selección de fuentes por parte de Rigoberto Iturriaga a partir del Archivo Histórico Franciscano permite hoy un acceso eficiente a los documentos, especialmente a los libros de las disposiciones y de cuentas. A su vez, el Proyecto «Rescate y difusión del Archivo del Monasterio de Clarisas de Antigua Fundación, Puente Alto, Santiago de Chile», financiado por el Programa para Bibliotecas y Archivos de Latinoamérica del Centro de Estudios de Latinoamérica David Rockefeller de la Universidad de Harvard, ha permitido la catalogación y digitalización del archivo del Monasterio de las Clarisas de Antigua Fundación (MCAF). Dicho fondo tiene la particularidad de haber conservado a través de los siglos 112 libros, con más de 61.000 manuscritos relativos a la historia de la orden entre 1605 y 1900 (http://www.uandes.cl/archivo-clarisas/) 
incluyendo: fundadores, montos donados, tipos de donaciones, propiedades cargadas, beneficios para los fundadores, compromisos de inversión por parte del monasterio, estados de cuentas, etc. Estos legajos se complementan con los libros de Profesiones, Dotes y Renuncias: documentos relativos a las postulantes al monasterio, sus familias, y bienes. Asimismo, completan el análisis las visitas pastorales: documentos que registran las incursiones de los diversos obispos al monasterio durante los siglos XVIII y XIX, con sus respectivos comentarios, amonestaciones, sugerencias, reglamentos, mandatos y normativas en general.

No solo la cantidad de registros que hicieron las Clarisas Antiguas para constatar los movimientos económicos al interior del claustro a lo largo del siglo XVIII, sino también, el nivel de detalle y la expertise con que aquellos fueron realizados; reflejan la importancia de la cotidianidad material para este monasterio y la estrecha vinculación que tenía dicha realidad con la vida religiosa de la comunidad que vivía y oraba tras los muros de la Cañada.

\section{REGLA Y POBREZA FRANCISCANA}

Francisco de Asís, modelo del fraile mendicante, motivaba a sus seguidores a vivir según las máximas del Evangelio, enfatizando la importancia del ideal de pobreza: «Si quieres ser perfecto, ve, vende todo lo que tienes y dáselo a los pobres, y tendrás un tesoro en el cielo; y ven, sígueme $(\mathrm{Mt}, 19,21) \gg^{21}$. Estas disposiciones figuraban en la Regla no bulada de los Hermanos Menores, escrita por el santo el año 1221 según consejo del cardenal Hugolino de Anagni (futuro Gregorio IX), donde también se detallaban normativas sobre la austeridad de los hábitos, el modo de servir y trabajar, y la prohibición de recibir dinero alguno: «Y los hermanos de ningún modo reciban ni hagan recibir, ni busquen ni hagan buscar, pecunia como limosna, ni dinero para algunas casas o lugares ${ }^{22}$. Sólo se admitía la obtención de limosnas según las necesidades de los hermanos o de los leprosos a quienes asistían. En aquellas ocasiones y, como se requería una mínima sobrevivencia, los frailes debían mendigar sin avergonzarse: «Y cuando sea necesario, vayan por limosna. Y no se avergüencen, y recuerden que nuestro Señor Jesucristo, el hijo de Dios vivo omnipotente, puso su rostro como piedra durísima y no se avergonzó» ${ }^{23}$.

21 San Francisco. Escritos \& Biografías. Documentos de la época, Madrid, 2007, p. 109.

22 San Francisco. Escritos... [ver n. 23], p. 115.

23 San Francisco. Escritos... [ver n. 23], p. 116. 
Pequeños cambios se introdujeron en la Regla bulada, aprobada por el papa Honorio III dos años más tarde (1223), fundamentalmente, la precisión y la disminución en la extensión del texto (pasó de XXIV a XII capítulos). La normativa acerca de la pobreza y las limosnas se mantuvieron sin modificaciones ${ }^{24}$.

En Chile, la pobreza franciscana generó desde sus comienzos posturas diferentes, las que se plasmaron en las Constituciones Municipales que se redactaban para cada convento ${ }^{25}$. La observancia del voto en cuestión causaba, en la práctica, un problema mayor a los hermanos, pues según los Estatutos Generales ${ }^{26}$ (1621) solo podían hacer uso de los bienes a ellos otorgados a través de un laico denominado síndico, quien recibía el dinero de las limosnas y controlaba los gastos e ingresos de los libros de cuentas bajo la supervisión y consejo de los Padres discretos $^{27}$. Estos últimos debieron llegar a acuerdos constantemente con los laicos y la jerarquía eclesiástica para sostener su actividad, de ahí entonces que la dependencia de la comunidad local para el sustento económico era de vital importancia. Es ilustrativo, por ejemplo, que los hermanos no tuviesen derecho a recibir parte del diezmo ni de usufructuar propiedades rurales ${ }^{28}$.

A diferencia de los frailes, la Regla de Santa Clara tuvo importantes alteraciones en sus primeros tiempos. La Regla de 1253, derivada de la impronta franciscana, estipulaba la absoluta pobreza prohibiendo la posesión de bienes temporales y las transacciones económicas de cualquier tipo. Así lo disponía la santa:

Y así como yo, juntamente con mis hermanas, fui siempre solícita de guardar la santa pobreza que prometimos al señor Dios y al bienaventurado Francisco, del mismo modo las abadesas que me sucedieren en el oficio y todas las hermanas estén obligadas a guardarla inviolablemente hasta el fin, esto es, a no recibir ni tener posesión o propiedad, ni por sí ni por interpuesta persona ${ }^{29}$.

Diez años después, aquella primera normativa se mitigaba con autorización del papa Urbano IV, al introducirse la clausura, las dotes y la posesión de propie-

24 San Francisco. Escritos... [ver n. 23], p. 130-138.

25 Algunos ejemplos son: SANTIAGO DE CHILE, ARCHIVO FRANCISCANO DE SANTIAGO DE CHILE [=AFSCh], Fondo S.T/Actas del Definitorio, Constitución del año 1680, vol. 1, fj. 49-50; AFSCh, Fondo S.T/Actas del Definitorio, Constitución del año 1712, vol. 2, fj. 183; SANTIAGO DE CHILE, ARCHIVO NACIONAL DE CHILE [=ANH], Fondo Varios, Constitución Municipal: Convento de La Recoleta, pieza 39, fj. 380-390.

26 Estatutos Generales de Barcelona para la familia cismontana de la Regular observancia de N.P.S. Francisco, Madrid, 1746, p. 18.

27 Manuel RevuelTa, La exclaustración (1833-1840), Madrid, 1976, p. 29.

28 Jorge Troisi MELEAN, Los franciscanos [ver n. 10], p. 123

29 Ignacio OmaecheverRía, Escritos de Santa Clara y documentos complementarios, Madrid, 1993, pp. 264-265. 
dades por parte de la comunidad para garantizar el sustento diario ${ }^{30}$. Estas transformaciones serán especialmente relevantes para comprender el contraste entre las prácticas masculinas y femeninas desenvueltas en los monasterios franciscanos de Santiago, y su consecuente diferencia en la observancia del voto de pobreza.

\section{FRANCISCANOS Y CLARISAS EN CHILE: EL VOTO DE POBREZA}

Alrededor de 1553, ya se encuentran en Chile los franciscanos. Fueron Pedro de Valdivia y el príncipe Felipe los impulsores de su llegada. Los frailes Martín de Robleda, Juan de Torralba, Cristóbal de Rabaneda, Juan de la Torre y el lego Francisco de Frejenal, provenientes de la Provincia de los XII, fueron sus fundadores ${ }^{31}$. En la capital del Reino, se establecieron en los terrenos ubicados en el cerro Huelén, donde en 1548 se había construido la Ermita de Santa Lucía, cuya existencia fue efímera. En abril de 1554, y a raíz de la donación de Rodrigo Quiroga, los religiosos ocuparon la Ermita del Socorro, en la vereda sur de la Cañada, actual Alameda.

Durante los siglos coloniales, este convento, también llamado Máximo o Grande, fue la casa matriz de la Provincia Santísima Trinidad. Se constituyó como el instituto más reputado donde ingresaban los novicios procedentes de diversas localidades del territorio. Fue el centro de las decisiones, siendo, salvo algunas excepciones, el lugar donde habitualmente se llevaban a cabo los Capítulos Provinciales.

En el caso de las mujeres, la espiritualidad franciscana llegó a Chile con la formación del monasterio antiguo de Santa Clara a fines de la década de 1560. Sus religiosas iniciaron la tradición de vida contemplativa femenina en este agreste y lejano territorio del Imperio español, agrupadas como beaterio en la ciudad de Osorno bajo la advocación de Santa Isabel de Hungría y dirigidas por Isabel de Landa $^{32}$. Tras la rebelión indígena de fines del siglo XVI, emprendieron una aza-

30 Victoria TRIVIÑo, El libro que da forma a la vida claustral: la regla de Santa Clara, en los 800 años de la fundación de las clarisas, 1212-2012), en Francisco CAMPOS, La clausura femenina en el Mundo Hispánico: una fidelidad secular, El Escorial, 2011, pp. 425-448.

31 Marciano Barrios, Presencia franciscana en Chile. Sintesis histórica 1553-2003, Santiago de Chile, 2003, pp. 33-41.

32 Pese a la relevancia histórica del monasterio antiguo de Santa Clara de Santiago de Chile, no existe a la fecha una publicación -crónica, artículo o libro- dedicada únicamente a describir y problematizar sus orígenes, desarrollo o situación actual. No obstante, conviene destacar algunos trabajos que han hecho importantes referencias: La provincia eclesiástica chilena: erección de obispados $y$ división en parroquias, Santiago de Chile, 1895; Gabriel GUARDA, La Edad Media de Chile... [ver n. 12]; Imelda CANO ROLDÁN, Las mujeres... [ver n. 18]. 
rosa travesía, que las obligó a huir primero a Chiloé y luego a la Isla Quiriquina para llegar más tarde a San Francisco del Monte, en las cercanías de Talagante. El año 1604 lograron finalmente instalar su monasterio en Santiago, a pasos del convento franciscano de la Alameda, y profesaron allí la segunda Regla de Santa Clara aprobada en 1263 por Urbano IV, como consecuencia de la colaboración que recibieron por parte de los frailes desde sus orígenes hasta su establecimiento en la capital del Reino. A mediados del siglo XVII comenzaron a ser llamadas como «Clarisas Antiguas», para diferenciarlas del segundo convento que la Orden fundó en Santiago ${ }^{33}$.

A mediados del siglo XVIII ambos monasterios tenían un lugar protagónico destacado no solo en la ciudad, al estar en uno y otro lado de la Cañada, sino también en la vida cotidiana de Santiago. Era común que las familias frecuentaran la iglesia de San Francisco, enviaran a sus hijas a educarse a las Clarisas, contaran con algún familiar tras las rejas del claustro, conocieran sus dulces y cerámicas, como también la labor evangelizadora de los franciscanos a lo largo del país.

Hacia 1770, los frailes habían visto crecer a la Orden, pues en 1645 se fundó el convento de la Recoleta Franciscana, en el lado norte del río Mapocho, en el barrio de la Chimba. Por su parte, la población dentro del monasterio de Santa Clara aumentó considerablemente, llegando a ser más de medio millar de mujeres las que lo habitaban, entre monjas de velo negro y blanco, seglares, donadas, criadas y esclavas. Se desprendió una nueva rama -las clarisas de la Victoria- en 1678, quienes se ubicaron en la Plaza de Armas. También se fundó en 1727 el monasterio de las Clarisas Capuchinas, que si bien, cuentan con otra regla, pertenecen a la familia franciscana ${ }^{34}$.

El siglo XVIII y el contexto de las reformas borbónicas representaron un periodo de cambio para las órdenes religiosas en Chile, tanto masculinas como femeninas, debido a la reorganización del clero regular ante su autonomía e incidencia y fortaleza económica. Por ejemplo, se limitó la función de los regulares en las doctrinas y parroquias, generándose un problema de atención pastoral de los feligreses y también de dificultades para sostener a los frailes en general, que

33 Juan de GuerniCa, El Monasterio de Clarisas de Nuestra Señora de la Victoria en sus cuatro periodos Santiago de Chile, 1944.

34 Marcial SÁNCHEZ, En las puertas del cielo, Clarisas capuchinas de Santiago de Chile: una fundación, 1727, en Horacio ARÁNGUIZ DONOSO y René Millar, Los franciscanos en Chile... [ver n. 14], pp. 149-169. 


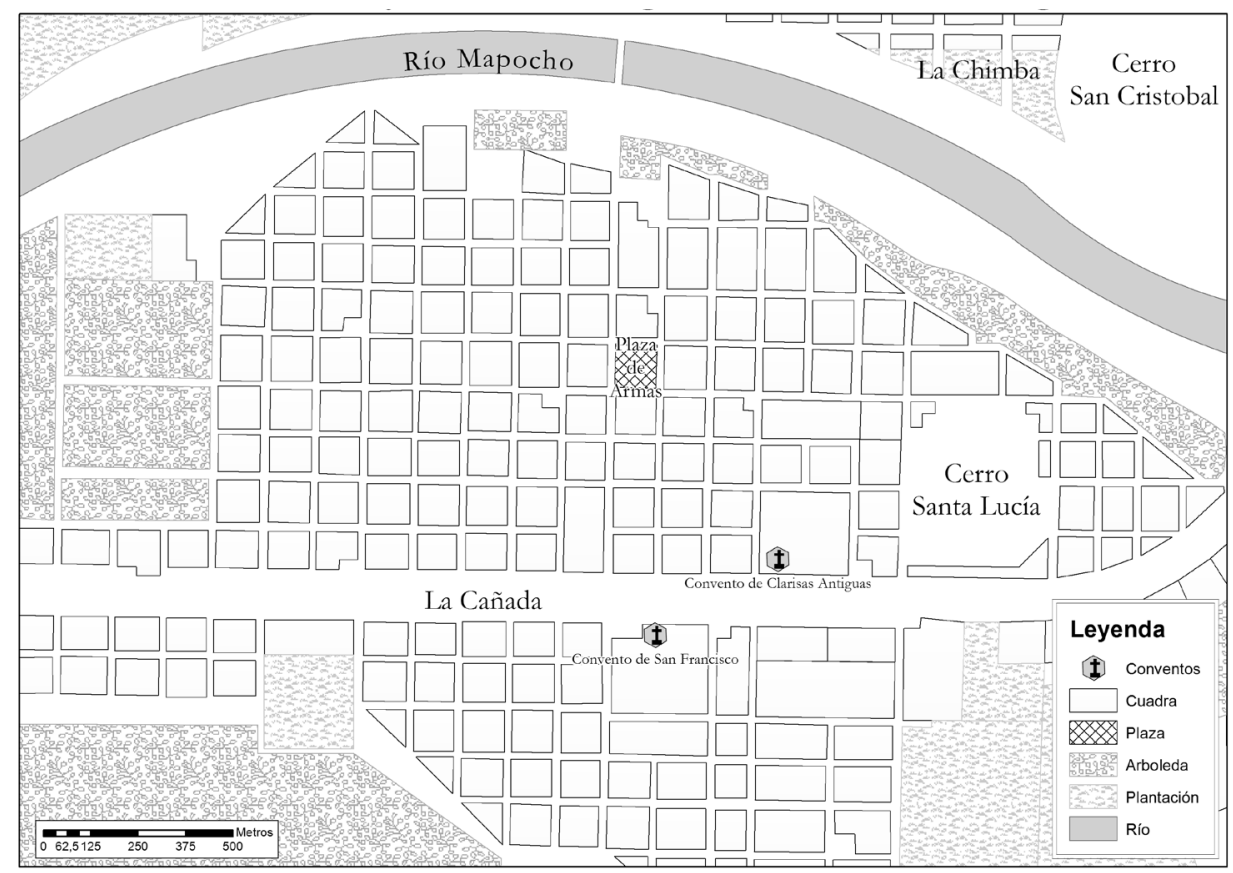

Franciscanos y Clarisas Antiguas en la Cañada de Santiago. Siglo XVIII. Fuente: Plano construido a partir del texto de Gabriel GuARDA, Historia urbana del Reino de Chile, Santiago, 1978, p. 304.

tenían una importante presencia en las diócesis ${ }^{35}$. En el caso de las Clarisas de la Cañada, se intensificaron las normativas eclesiásticas, especialmente por parte del prelado Manuel de Alday para recuperar la Regla primitiva de la Orden y la vida en común. Amonestaciones y correspondencia se refieren a la clausura, el silencio y particularmente la pobreza, la cual se transgredía, a juicio del obispo, a través de las vestimentas, las fiestas y las comidas ${ }^{36}$.

35 En el caso chileno, para el período 1760-1810, Lucrecia Enríquez, cuantificó dicha presencia, dando como resultado que los franciscanos fueron unos de los que más sirvieron en parroquias como tenientes curas en el obispado de Santiago. Lucrecia ENRÍQUEZ AGRAZAR, Regulares en la Iglesia secular: Presencia franciscana en curatos y doctrinas del obispado de Santiago de Chile, 1760-1810, en René MillaR y Horacio ARÁNGUIZ DonOSO, Los franciscanos en Chile... [ver: n. 14], pp. 197215.

36 SANTIAGO DE CHILE, ARCHIVO DEL MONASTERIO DE SANTA CLARA DE ANTIGUA FUNDACIÓN [=MCAF], Orden y Regla, Auto de visita de Manuel de Alday y Aspée, vol. 91, 30 de marzo de 1756, fj. 58-61; Auto de visita de Manuel de Alday y Aspée, vol. 91, 17 de abril de 1759, fj. 95; Auto de visita de Manuel de Alday y Aspée, vol. 91, 3 de febrero de 1787, fj. 83. 


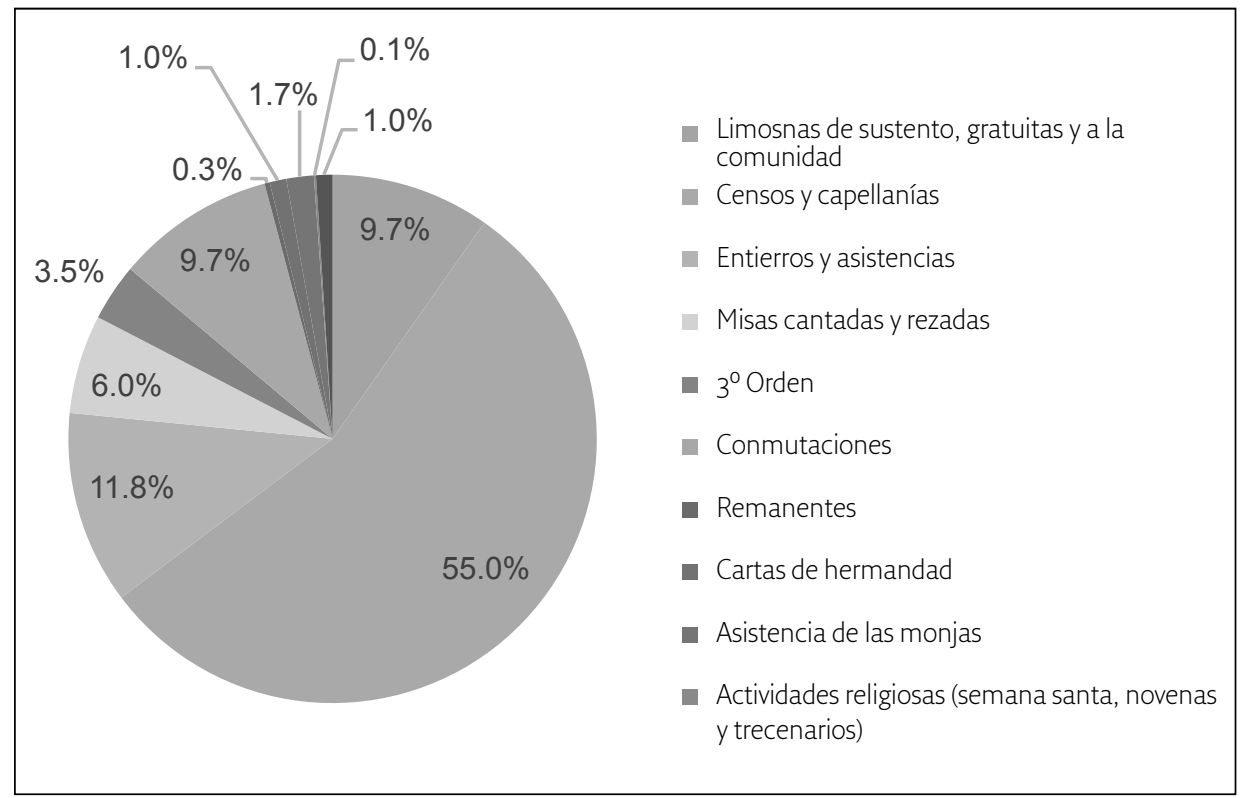

Entradas en plata física. Convento de la Alameda de Santiago de Chile. 1805-1825. Fuente: Elaboración propia a partir de Rigoberto ITURRIAGA, Disposiciones del Convento San Francisco de Santiago, 1796-1828, Santiago de Chile, ก. 82,2005 .

\section{INGRESOS: DINERO Y METAL}

Durante las últimas décadas del siglo XVIII los monasterios franciscanos de la Cañada, a pesar de haber sido cuestionados por la autoridad civil y eclesiástica, continuaron con sus prácticas económicas, cuyos registros permiten visualizar hoy, en qué medida se adherían al voto de pobreza que les era propio.

Para los frailes, si bien la Regla señalaba que sus ingresos debían limitarse a las limosnas; las fuentes develan que las principales entradas económicas provenían también de la atención pastoral que desempeñaba el convento: de entierros y asistencias, misas (cantadas y rezadas), aportes de la Orden Tercera, atendida por los frailes, conmutaciones, cartas de hermandad, asistencia a otros institutos religiosos, censos y capellanías, entre otros. Por ejemplo, en términos porcentuales, las entradas más significativas del convento de la Alameda para el período 1805-1825, las constituyeron los censos y capellanías, con un $55 \%$ del total que ingresaba en plata. Luego le seguían los entierros y asistencias con un $11,8 \%$, y a continuación las limosnas de la calle o del sus- 


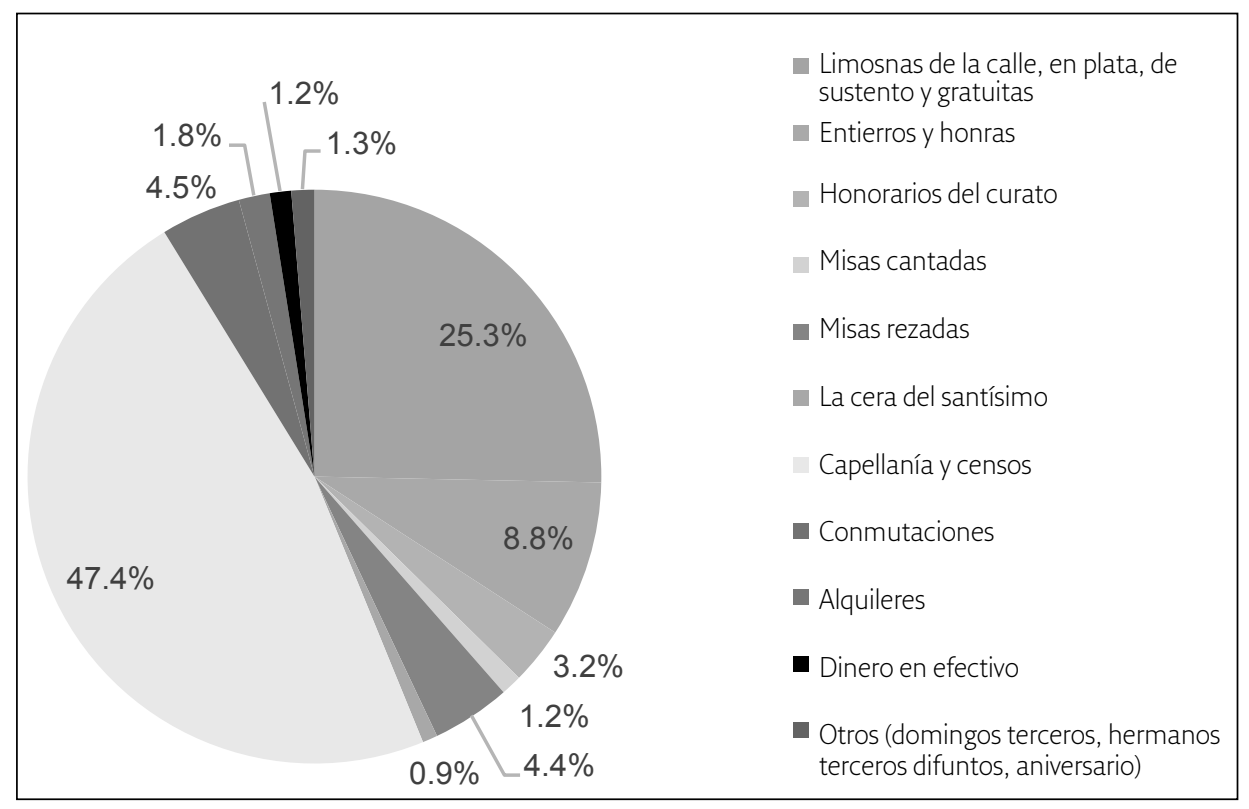

Entradas en plata física por período. Convento Franciscano de la Recoleta de Santiago. 1805-1837. Fuente: Elaboración propia a partir de: Cristián LEAL, La Recoleta Franciscana de Santiago: Fuentes para su estudio: Libro de la Disposición, 1805-1837, Santiago de Chile, n. ${ }^{0}$ 99, 2008.

tento y las conmutaciones con un $9,7 \%{ }^{37}$. Tales entradas correspondían al $87 \%$ de los ingresos al convento, evidenciando, por un lado, la estrecha vinculación espiritual de los seglares con los frailes y por otro, la abundancia de algunos productos (trigo, animales, vino) que permitían al convento conmutar las especies por dinero ${ }^{38}$.

Situación similar observamos en otro convento de la Orden en Santiago, el de la Recoleta. Localizado en el populoso barrio de la Chimba, para el período 1805-1837, éste presentaba entradas por los siguientes conceptos: limosna de la calle, entierros y honras, honorarios del curato, misas cantadas y rezadas, cera del santísimo, capellanías y censos, conmutaciones, alquileres y remanentes del período anterior. Nuevamente los censos y capellanías eran las entradas en dinero más sustantivas, con un $47 \%$ del total, seguidos de la limosna de la calle con un

37 Rigoberto ItUrRIaga, Disposiciones del Convento San Francisco de Santiago, 1796-1828, Santiago de Chile, n. ${ }^{\circ} 82,2005$.

38 Rigoberto ITURRIAGA, Disposiciones... [ver n. 36]. 
$25,3 \%$ y los entierros y honras con un $8,8 \%$. En total superaban el $80 \%$ de las entradas ${ }^{39}$.

Las clarisas tenían un régimen de ingresos diferente al de los frailes debido a la clausura monástica, especial obsequio que las consagradas hacían a Jesucristo $^{40}$. Luego de la reforma de la Regla en 1263, vigente en los conventos chilenos, contaban con la dote, figura económica que se replicó en los claustros femeninos al menos hasta el siglo XX. Las dotes entregadas por las postulantes al momento de ingresar al claustro, o bien, siendo novicias prontas a recibir la profesión religiosa, constituyeron entonces el principal mecanismo de financiamiento del monasterio, permitiendo el sustento de las monjas en cuanto a vestimenta, alimentación, habitación (posible compra de celda propia) y atención de enfermedades y epidemias.

Pese a que los montos que debían entregar las Clarisas Antiguas según el tipo de velo no tenían un origen preciso; la costumbre había señalado con el tiempo que las de velo negro debían pagar 2.265 pesos y las de velo blanco $800^{41}$. Sin embargo, tales montos se adecuaron a lo largo del siglo, para posibilitar el ingreso de mujeres con conocimientos musicales y de oficios domésticos y manuales. Esta práctica fue altamente criticada por las autoridades eclesiásticas, no solo por desarticular las jerarquías sociales que organizaban a la comunidad conventual intramuros, sino porque implicaba graves desajustes económicos, especialmente en una época en que el sistema de censos ya presentaba grietas,

39 Cristián LEAL, La Recoleta Franciscana de Santiago: Fuentes para su estudio: Libro de la Disposición, 1805-1837, Santiago de Chile, n. ${ }^{\circ}$ 99, 2008.

40 La clausura monástica fue definida en 1708 por el obispo de Santiago, Luis Francisco Romero, como la confluencia entre el recogimiento de los sentidos y la custodia del cuerpo. Estaba estipulada en la segunda regla Clarisa del año 1263, y fue promulgada como deber para todos los monasterios femeninos en el Concilio de Trento (1545-1563), cuyas conclusiones se difundieron en el Virreinato del Perú a través de los Concilios Limenses celebrados en las décadas de 1560 y 1580. MCAF, Auto sobre la clausura del Monasterio, vol. 91, 21 de septiembre de 1708, en, fj.4. También en cap. V del Concilio de Trento: «Providencias sobre la clausura y custodia de las monjas», El sacrosanto y ecuménico Concilio de Trento, Barcelona, 1847, pp. 337-338.

41 Durante la época colonial, el monto de la dote monástica dependía de cada institución religiosa. Por ejemplo, la dote de las monjas agustinas fue fijada al momento de su fundación en 2.340 pesos, mientras que la de las Clarisas de la Victoria alcanzó los 2.250 pesos. Un caso especial era el de las Capuchinas, pues de acuerdo a sus constituciones no se exigía dote para ingresar al convento, como lo hacía presente el Obispo de Santiago en 1722 al solicitar su establecimiento y recalcaba el Rey Felipe V en la real cédula que autorizaba su fundación. Ver: René MILLAR y Carmen DUHART, La vida en los claustros... [ver n. 13], p. 130. El origen de la cantidad exigida por las Clarisas Antiguas aún es un misterio, sin embargo, se maneja la hipótesis de que haya sido la costumbre la que guio esta práctica conventual, desde principios del siglo XVIII. 
como manifestaban los autos de visita de los obispos, Alejo Fernando de Rojas y Juan González de Melgarejo, en los años 1721 y $1745^{42}$. Desde la década de 1760 en adelante, dada la flexibilización de la dote -especialmente para el caso de la monja de velo negro- se inició un proceso caracterizado por la disminución de la cantidad total aportada por las profesas y por la incapacidad, en algunas oportunidades, de ofrecer dote completa; situación que se torna evidente en los inicios del siglo $\mathrm{XIX}^{43}$.

Las seculares que habitaban el claustro en el siglo XVIII -educandas, novicias y seglares adultas o pensionistas- debían costear su recogimiento al interior del claustro a partir de un determinado «derecho de piso». Debían pagar según el obispo Luis Francisco Romero 25 pesos cada año, valor que la abadesa podía aminorar según la calidad y necesidad de cada persona, sin embargo, esta cantidad fue rebajada a 12 pesos por el obispo Manuel de Alday, unas décadas más tarde ${ }^{44}$. En la práctica, solo educandas y seglares adultas pagaron dicha cantidad, mientras que las novicias cancelaron entre 40 y 60 pesos anuales, según el tipo de velo al que aspiraban. Quienes deseaban profesar con la categoría de velo negro pagaban 60, algunos ejemplos fueron: Mercedes y Clara Almarza, Francisca Echaurren, María Mercedes de la Fuente y María del Rosario Breton. Disminuía a 40 este valor para quienes aspiraban al velo blanco, como fue el caso de María de las Nieves Labra, Javiera Cotapos y María de los Dolores Tagle ${ }^{45}$.

$\mathrm{Al}$ igual que los frailes, las clarisas se beneficiaron de los censos y las capellanías, pese a la dificultad administrativa que implicaba realizar las cobranzas y llevar a cabo las causas ejecutivas frente a quienes no pagaban los réditos correspondientes ${ }^{46}$. En el cambio de siglo, las cantidades percibidas anualmente por

42 Alejandro Fernando de Rojas señalaba: «Los atrasos de las rentas del monasterio, piden que se minoren todos los gastos, que se pudieren omitir». MCAF, Visita de Alejo Fernando de Rojas y Acebedo, vol. 91, 13 de octubre de 1721, fj.15. Unas décadas más tarde, Melgarejo también hacía énfasis en las pérdidas que el monasterio había tenido a partir de los censos: «Y por que tenemos Conozimiento de la Grande Decadencia que tienen los sensos de los monasterios que apenas pueden mantenerse que no se admita en adelante revaja alguna en las Dotes de estas monjas sino es en Casso mui particular y con Disposicion del Juez Eclesiástico Ordinario por el grabe perjuicio que se Reconose en las muchas Rebajas que habido en los tiempos antesedentes». MCAF, Visita de Juan González Melgarejo, vol. 91, 9 de septiembre de 1745, fj. 33v.

43 Alejandra FUENTES, Mujeres y vida monástica en Chile colonial: jerarquías sociales y religiosas en el Monasterio Antiguo de Santa Clara, Santiago, 1678-1825, Tesis para optar al grado de Magíster en Historia, Universidad de los Andes, Chile, 2017, Inédita.

44 MCAF, vol. 91, fj. 59v.

45 MCAF, vol. 55, sin foja (foto 232).

46 Por ejemplo, las autoridades del Reino recomendaban a las religiosas en el año 1752: no admitir géneros de mala calidad para pagar aquellos intereses, averiguar rigurosamente a cuánto equi- 
tales censos fueron disminuyendo: entre abril de 1765 y mayo de 1768 , el síndico del monasterio Pedro Nolasco González, recaudó 32.214 pesos en total, es decir, un promedio de $10.738 \mathrm{al} \mathrm{año}^{47}$; mientras que entre septiembre de $1816 \mathrm{y}$ febrero de 1817, Rafael Beltrán solo pudo recaudar 3.227 pesos durante 6 meses, un eventual promedio de 6.454 pesos anuales ${ }^{48}$. En 1825 , este último síndico solo recibió 713 pesos $^{49}$.

Respecto a las propiedades, el monasterio antiguo de Santa Clara miraba con añoranza aquellos años en que recibía los productos de la estancia de Tango y de la chacra de Peñalolén, vendidas en la década de 1730 para contrarrestar los daños que dejó el terremoto en el edificio conventual ${ }^{50}$. En aquella época, solo contaba con los alquileres de un par de propiedades urbanas que poseía en la ciudad de Santiago ${ }^{51}$.

\section{GASTOS DE COMUNIDAD}

$\mathrm{Al}$ analizar la economía de ambos monasterios bajo la interrogante de la observancia del voto de pobreza, llama la atención a primera vista la cantidad de ítems considerados en sus libros de cuentas. Existen gastos propios de la vida en

valían las rentas por cobrar, hacer un registro de los deudores y de las fincas impuestas a censo, además de consumir el caudal existente del monasterio con «buena economía y arreglamiento para que no se desperdicie nada en perjuicio de la pobreza religiosa». MCAF, Acuso de resulta de Pedro de Tula Basan, 17 de diciembre de 1752, vol. 91, fj. 55v-56v.

47 MCAF, vol. 61, fj. 70-76.

48 MCAF, vol. 66, sin fojas (foto 25 y ss.).

49 MCAF, vol. 67, sin foja (foto 39).

50 Tenemos constancia de que Tango se vendió entre los años 1730 y 1756, ya que en esta última fecha se construyeron nuevos dormitorios y oficinas de comunidad con las ganancias de esta transacción. Se obtuvieron 10.500 pesos, de los cuales 6.000 se impusieron a censo y 4.500 se gastaron en las obras señaladas. MCAF, vol. 52, fj. 12-15v. Respecto a Peñalolén, la bibliografía señala que habría sido vendida en esta misma época al comerciante español Miguel Antonio de Vicuña, sin embargo, dicha información no se ha podido constatar en el archivo conventual de la orden. Juan Guillermo MUÑOZ, Viñas en la traza de Santiago del Nuevo Extremo y chacras colindantes (siglos XVIXVII), en Revista de Historia social y de las mentalidades, 10 (2006), pp. 24-25. [http://www.revistas. usach.cl/ojs/index.php/historiasocial/article/viewFile/367/361]; Domingo ARTEAGA, Colección de bistoriadores de Chile y documentos relativos a la Historia Nacional, tomo XLVIII, Santiago de Chile, 1941, pp. 110-115.

51 Por ejemplo, el año 1817 , la comunidad recibió 201.3 pesos por el arriendo de dos casitas y cuatro cuartos, y al año siguiente, obtuvo por la misma razón, 196.4 pesos. No obstante, dichos inmuebles fueron utilizados durante varios meses por el recién formado Gobierno sin que el monasterio recibiese pago alguno. MCAF, vol. 66, sin fojas (fotos 73-75). 
comunidad imposibles de evitar, este trabajo se pregunta por aquellos que en la época podían considerarse accesorios o suntuarios, por lo tanto, reñidos con la debida austeridad seráfica.

Para el caso de los frailes, las fuentes arrojan movimientos económicos múltiples y variados para una comunidad que alcanzaba el centenar de personas, entre sacerdotes, legos y donados ${ }^{52}$. La compra de alimento, para cubrir el gasto de Plaza o diario que tenían los conventos, implicaba la adquisición de diferentes carnes, como vaca, cerdo y cordero; derivados de ellas, interiores como guatitas, ubres y criadillas, y carne seca como charqui. Completaban la dieta pescados y mariscos, frescos y secos, y entre los tipos eran comunes la pescadilla, la corvina, el congrio, el cochayuyo y el luche. Las legumbres, fundamentales en la alimentación, incluían lentejas, garbanzos y porotos. Asimismo, las listas incluían pan, verduras, huevos, grasa, manteca, ají, aceite, arroz, chuchoca y zapallos.

Los sueldos parecen ser uno de los gastos más sustantivos, correspondían a aquellos laicos que prestaban servicios al interior de los conventos y en las chacras, desde el ámbito de la higiene y la salud hasta las labores agrícolas. Se cuentan en la lista de beneficiados: médicos, enfermeros, sangradores, barberos, cuidadoras de enfermos, molineros, chancheros, agrimensores, procuradores, carpinteros, hortelanos, podadores, pastores, panaderos, serenos, cocineros, lavanderas, peones de huerta y de servicio, coheteros, músicos, bronceros, relojeros, fonderos, abogados, síndicos, etc.

Los desembolsos en ornamentos sagrados eran también de importancia. En las disposiciones aparecen registrados la compra de misales, vinajeras, copones, casullas, cíngulos, lazos, vestidos para las imágenes de la virgen y los santos, estolas, ropa interior y zapatos. Un gasto considerable fue la constante reparación de los conventos, los cuales sufrían el natural deterioro de los años, las inclemencias del tiempo y los devastadores terremotos ${ }^{53}$, significando una considerable cantidad de dinero en la compra de materiales, herramientas y el correspondiente pago a los operarios. En la misma línea destacan los costos de las celebraciones en las fiestas litúrgicas, especialmente la de San Francisco,

52 AFSCh, Carpeta s/n, Informe del n. ${ }^{\circ}$ de Religiosos. Fr. Buenaventura de Aránguiz, Documento n. ${ }^{\circ} 49,1814$; ANH, Fondo Capitanía General, Nómina de los religiosos de esta Provincia de la Santísima Trinidad del Reyno de Chile, de N.P. San Francisco, según edad procedencia y parcialidad, vol. 664, 1814, fj. 14-22.

53 Alfredo PaLACIOS, Fuentes para la Historia sísmica de Chile (1570-1906), Santiago de Chile, 2016. 
ocasión en que compraban chocolate, mistela, dulces helados y fuegos artificiales $^{54}$.

La gran cantidad de personas que conformaban el monasterio de Santa Clara de Antigua Fundación a fines del siglo XVIII y comienzos del XX, explica la mayor diversidad de gastos con respecto al convento de la vereda sur de la Cañada. Siendo más de quinientas mujeres las que convivían en el claustro -entre religiosas y seglares- y en virtud de que su vida cotidiana se limitaba a los muros de la clausura; sus necesidades fueron diferentes a las de los frailes ${ }^{55}$.

Así como el consumo de alimentos fue muy similar, los sueldos deben considerarse bajo el agravante de que algunas personas que vivían dentro del monasterio, como por ejemplo los criados del servicio doméstico, en vez de recibir un pago en dinero contaban con comida, techo y abrigo; práctica económica y social que dificulta calcular realmente cuánto se gastaba para mantenerlos. Además, diversas necesidades administrativas suscitaban el pago de síndicos, abogados, contadores y procuradores para sobrellevar las complejas cuentas del convento y, de manera particular, las causas ejecutivas que se iniciaban cuando los deudores no pagaban los réditos de los censos que habían concertado ${ }^{56}$. A esto se sumaban las limosnas y también los ejercicios espirituales y las obras pías que requerían la colaboración de confesores y capellanes ${ }^{57}$.

Transgrediendo abiertamente la normativa de su propia Regla y las disposiciones episcopales, las clarisas desembolsaban en costosas y lujosas vestimentas, no solo para engalanar el hábito de las religiosas sino también el vestido de las seglares que vivían en el claustro junto con ellas. Como afirmaba el obispo Romero en 1713 , criadas y educandas usaban trajes de seda «poco modestos», sin

54 Disposición del convento máximo de Nuestra Señora del Socorro de la ciudad de Santiago de Chile en 19 de marzo de 1819, por el padre guardián Fray Fosé A. de Alcáza, en Rigoberto ITURRIAGA, Disposiciones del... [ver n. 34], p. 96.

55 Testimonian esta realidad las expediciones de viajeros y científicos que llegan al Reino durante el siglo XVIII, y las constantes amonestaciones que recibieron estas religiosas por la presencia de niñas educandas, seglares adultas y criados. Alejandro Malaspina, por ejemplo, a través de las noticias que le proporcionó Juan José de Santa Cruz y Silva, observó alrededor de 400 mujeres, incluidas las monjas, las criadas y las niñas de educación. Reafirman tales consideraciones las anotaciones que realizó en la segunda mitad del siglo XVIII el comerciante y soldado español, José Antonio Pérez, quien señaló que los monasterios de Agustinas y Claras eran muy numerosos, a diferencia de los claustros del Carmen, las Capuchinas y las Monjas Rosas. Ver: Rafael SAGREDO, La expedición Malaspina en la frontera austral del imperio español, Santiago de Chile, 2004, pp. 473474; Domingo ARTEAGA, Colección de Historiadores de Chile y documentos relativos a la Historia Nacional, tomo XXII, Santiago de Chile, 1900, p. 84.

56 MCAF, vols. 17, 29, 18, 38 y 106.

$57 \mathrm{El}$ archivo conventual no registra libros de capellanías específicos para el siglo XVIII. 
faldellines y decorados con alegres cintas de colores ${ }^{58}$. Dicha práctica había intentado ser controlada desde fines del siglo XVII por el Sínodo del obispo Bernardo Carrasco y Saavedra (1688), que disponía que todas las seglares que se educaban en los monasterios de monjas del Reino de Chile no vistieran telas lujosas como lamas, cambrayes, encajes y puntas, porque contravenían justamente el voto de pobreza $^{59}$.

Las visitas de médicos, barberos y sangradores; y la preparación de medicinas y alimentación especial, formaban parte de los cuantiosos gastos que se llevaban a cabo para cuidar el cuerpo y la salud de las religiosas. El hecho de haber contado con el oficio de enfermera y con un importante espacio dentro del monasterio destinado al cuidado de las profesas aquejadas por algún mal, demuestra la presencia permanente de la enfermedad dentro de la comunidad clarisa y los costos asociados a ésta ${ }^{60}$. Junto con ello, destacaron los desembolsos con ocasión de la muerte, los que incluían misas y sepulturas tanto para monjas como para seglares ${ }^{61}$.

Así como los frailes solo honraban con boato al santo fundador, las clarisas agregaban Semana Santa, Pascua, Navidad, Santa Clara, la Expectación del parto de la Virgen y el Aniversario de las Ánimas; junto con los festejos vinculados a las tomas de hábito y profesiones, y a los ingresos de autoridades civiles y eclesiásticas. Todas ellas tenían una cara mundana que mostraba a los establecimientos monásticos femeninos no solo como lugares de recogimiento y piedad, sino también como escenario propicio para la vida social y para algunas frívolas y galantes diversiones ${ }^{62}$. En aquellas instancias, el monasterio de la Cañada invertía en banquetes, decoraciones, músicos, fuegos artificiales, ornamentos litúrgicos, chocolate, sermones, criados, peones, e inclusive, en curiosas manualidades con las cuales las monjas agasajaban a sus invitados ${ }^{63}$.

58 MCAF, vols. 91, fj. 8-9v.

59 Bernardo CARRaSCO, Sínodo diocesano que celebró el Ilustrísimo i Reverendísimo señor, Doctor Maestro Don Frai Bernardo Carrasco i Saavedra, Obispo de Santiago de Chile, 1688, en Eduardo DunIGAN, Sinodos diocesanos del Arzobispado de Santiago, Nueva York, 1858, p. 49.

60 Por ejemplo, María de los Dolores Briceño fue aceptada como novicia el 10 de diciembre de 1807 por «tener fuerzas y práctica en asistencia de enfermos». MCAF, vol. 99, sin fojas (fotos 32-35).

61 Por ejemplo, para financiar el funeral de la religiosa María Ignacia de la Morandé en noviembre del año 1801, se pagaron 100 pesos. MCAF, vol. 65, fj. 30v.

62 Isabel CruZ, La fiesta. Metamorfosis de lo cotidiano, Santiago de Chile, 1995, p. 221.

63 Así lo demuestran las celebraciones que las religiosas desarrollaban en honor a Santa Clara, durante el mes de agosto de cada año, por ejemplos: la fiesta del año 1799, ilustrada en la tabla citada; y la fiesta del año 1800 registrada en MCAF, vol. 65, fj. 19v-20. 
Gastos efectuados por las monjas para la fiesta de Santa Clara. Año 1799

\begin{tabular}{|lc|}
\hline \multicolumn{1}{|c|}{ Ítem } & $\begin{array}{c}\text { Gasto } \\
\text { (en pesos; reales) }\end{array}$ \\
\hline A las religiosas de velo negro se le dieron & 56 \\
\hline A las de velo blanco & 21 \\
\hline Al Padre del sermón & 25 \\
\hline A los que sirvieron en víspera y día & 20 \\
\hline A los Cajeros y Pitos & $8 ; 4$ \\
\hline Al primer Sacristán & 20 \\
\hline Al segundo Sacristán & 14 \\
\hline A las criadas de la Sacristía & $20 ; 2$ \\
\hline A las enfermeras y criadas para zapatos & 6 \\
\hline A las seglares cantoras y demás sirvientes & $10 ; 2$ \\
\hline A las que ayudaron a servir en la celda abadesal & 10 \\
\hline En el diario de dicha Madre & 66 \\
\hline
\end{tabular}

Fuente: Tabla elaborada en base a los documentos contenidos en MCAF, vol. 65, fj. 17v-18.

Finalmente, no pueden dejar de mencionarse las constantes refacciones al edificio conventual que también necesitó este claustro femenino a lo largo del siglo XVIII, situación que se explica por el mantenimiento de una población cada vez más extensa, los constantes desastres naturales que azotaron la ciudad de Santiago durante la época y las exigencias del gobierno chileno tras el proceso de Independencia ${ }^{64}$. La ejecución de estas construcciones y reparaciones suscitó el ingreso periódico de carpinteros, albañiles, herreros y armadores. Además de este tipo de tareas, otros peones recibían sueldos por servir en las fiestas religiosas, sacar la basura y moler almendras que se compraban con el objetivo de obtener aceite para proveer las lámparas del convento ${ }^{65}$.

$64 \mathrm{El}$ año 1817, el gobierno de Chile ordenó enlucir y blanquear las murallas del convento, además de poner faroles para iluminar su Iglesia.

65 MCAF, vol. 63, fj. 35. 


\section{CONCLUSIONES}

Así como la vida cotidiana de frailes y monjas franciscanos se puede recrear a través de las fuentes conventuales, para comprender en qué medida se observaba el voto de pobreza en los conventos chilenos durante el tránsito del siglo XVIII al XIX, es clave la confrontación de las prácticas contenidas en sendos archivos monásticos con la espiritualidad de los santos de Asís: San Francisco y Santa Clara. Es ese vínculo entre la norma y su aplicación el que justamente diferenciaba a los franciscanos y las clarisas de la Cañada de Santiago. Si bien ambos debían estar apegados a la austeridad seráfica, fue la misma Regla y su mitigación la que permitió los «excesos» que apartaron a las religiosas del ideal de la fundadora, a diferencia de los textos legislativos para los Hermanos Menores, que no sufrieron cambios significativos en este aspecto. Tal como los frailes debían salir a evangelizar en el siglo, con las consiguientes penurias y sacrificios que implicaba transitar por un territorio extenso y precario; las clarisas permanecían intramuros y protegidas gracias a la clausura. Fue esa condición de «encierro», junto con el requisito de la dote y la imposibilidad de salir al mundo tras la limosna, los factores que -aceptados por las autoridades y por la tradición-, paradojalmente explicarían que las monjas se distanciaran más que los frailes del voto de pobreza según la «letra» de la Regla.

\section{REFERENCIAS BIBLIOGRÁFICAS}

\section{Archivisticas}

SANTIAGO DE CHILE, ARCHIVO DEL MONASTERIO DE SANTA CLARA DE ANTIGUA FUNDACIÓN [=MCAF], vol. 17, 18, 29, 38, 52, 55, 61, 63, 65, 66, 67, 91, 99, 106.

SANTIAGO DE CHILE, ARCHIVO FRANCISCANO DE SANTIAGO DE CHILE [=AFSCh], Fondo S.T/ Actas del Definitorio, Constitución del año 1680, vol. 1, fj. 49-50. Constitución del año 1712, vol. 2, fj. 183; Carpeta s/n, Informe del n. ${ }^{\circ}$ de Religiosos. Fr. Buenaventura de Aránguiz, Documento n. ${ }^{\circ} 49,1814$.

SANTIAGo DE CHILE, ARCHIVO NACIONAL DE CHILE [=ANH], Fondo Varios, Constitución Municipal: Convento de La Recoleta, pieza 39, fj. 380-390; Fondo Capitanía General, Nómina de los religiosos de esta Provincia de la Santísima Trinidad del Reyno de Chile, de N.P. San Francisco, según edad procedencia y parcialidad, vol. 664, 1814, fj. 14-22.

\section{Bibliográficas}

ARTEAgA, Domingo, Colección de historiadores de Chile y documentos relativos a la Historia Nacional, tomo XLVIII, Santiago de Chile, 1941. 


\section{CRISTIÁN LEAL PINO/ALEXANDRINE DE LA TAILLE/ALEJANDRA FUENTES GONZÁLEZ}

- Colección de Historiadores de Chile y documentos relativos a la Historia Nacional, tomo XXII, Santiago de Chile, 1900.

BARRIOS, Marciano, Presencia franciscana en Chile. Síntesis histórica 1553-2003, Santiago de Chile, 2003.

BRADING, David, El clero mexicano y el movimiento insurgente de 1810, en Revista Relaciones, 5 (invierno 1981), pp. 5-26.

CANO, Imelda, Las mujeres en el Reyno de Chile, Santiago de Chile, 1981.

CARrasco, Bernardo, Sínodo diocesano que celebró el Ilustrísimo i Reverendísimo señor, Doctor Maestro Don Frai Bernardo Carrasco i Saavedra, Obispo de Santiago de Chile, 1688, en Eduardo DUNIGAN, Sínodos diocesanos del Arzobispado de Santiago, Nueva York, 1858.

CruZ, Isabel, La fiesta. Metamorfosis de lo cotidiano, Santiago de Chile, 1995.

Di Stefano, Roberto y ZanaTTA, Loris, Historia de la Iglesia Argentina, Buenos Aires, 2009.

Di STEFANO, Roberto, El púlpito y la plaza. Clero, sociedad y política de la monarquía católica a la república rosista, Buenos Aires, 2004.

Estatutos Generales de Barcelona para la familia cismontana de la Regular observancia de N.P.S. Francisco, Madrid, 1746.

El sacrosanto y ecuménico Concilio de Trento, Barcelona, 1847.

ENRÍQUeZ AgRAZAR, Lucrecia, Regulares en la Iglesia secular: Presencia franciscana en curatos y doctrinas del obispado de Santiago de Chile, 1760-1810, en René MILlar y Horacio ARÁNGUIZ Donoso (eds.), Los franciscanos en Chile: Una historia de 450 años, Santiago de Chile, 2005, pp. 197-215.

FRASCHINA, Alicia, Ilustración y modernidad en los conventos de monjas de Buenos Aires: 1754-1833. Reformas y continuidades, en Hispania Sacra, LX/122 (2008), pp. 445-466.

FUENTES, Alejandra, Mujeres y vida monástica en Chile colonial: jerarquías sociales y religiosas en el Monasterio Antiguo de Santa Clara, Santiago, 1678-1825, Tesis para optar al grado de Magíster en Historia, Universidad de los Andes, Chile, 2017, Inédita.

GUARDA, Gabriel, La Edad Media de Chile. Historia de la Iglesia desde la fundación de Santiago a la incorporación de Chiloé, 1541-1826, Santiago de Chile, 2011.

GuERrA, Alejandra, Devociones y devotos en Santiago de Chile (1760-1800), Consideraciones en torno al estudio de las realidades materiales e inmateriales de las prácticas religiosas tardo-coloniales, en Eduardo CAVIERES y Juan CÁCERES (eds.), Lecturas y (RE) lecturas en historia colonial, Valparaíso, pp. 125-140.

GUERNICA, Juan de, El Monasterio de Clarisas de Nuestra Señora de la Victoria en sus cuatro periodos Santiago de Chile, 1944.

HorvitZ, María Eugenia, Memoria del nombre y salvación eterna. Los notables y las capellanías de misas en Chile (1557-1930), Santiago de Chile, 2006.

ITURRIAGA, Rigoberto, Disposiciones del Convento San Francisco de Santiago, 1796-1828, Santiago de Chile, n. ${ }^{\circ}$ 82, 2005.

LAVRIN, Asunción, Cofradías novobispanas: economias material y espiritual, en Gisela VON WOBESER, María MARTÍNEZ y Juan MUÑOZ (coords.), Cofradías, capellanías y obras pías en la América colonial (Serie Historia Novohispana, 61, Universidad Nacional Autónoma de México), México, 1998, pp. 49-64.

La provincia eclesiástica chilena: erección de obispados y división en parroquias, Santiago de Chile, 1895. LEAL, Cristián, La Recoleta Franciscana de Santiago: Fuentes para su estudio: Libro de la Disposición, 1805-1837, Santiago de Chile, n. ${ }^{\circ}$ 99, 2008. 


\section{POBREZA FRANCISCANA Y ECONOMÍA MONÁSTICA}

MAYO, Carlos y PEIRE, Jaime, Iglesia y crédito colonial: La política crediticia de los conventos de Buenos Aires (1767-1810), en Revista de Historia de América, 12 (1991), p. 75.

MiLlar, René y DUHART, Carmen, La vida en los claustros: Monjas y frailes, disciplinas y devociones, en Cristián GAZMURI y Rafael SAgREDo (eds.), Historia de la vida privada en Chile. El Chile tradicional de la conquista a 1840, Santiago de Chile, 2007, pp. 125-159.

Millar, René y ArÁNGUIZ DONOSO, Horacio (eds.), Los franciscanos en Chile: Una bistoria de 450 años, Santiago de Chile, 2005.

MUÑOZ, Juan Guillermo, Viñas en la traza de Santiago del Nuevo Extremo y chacras colindantes (siglos XVI-XVII), en Revista de Historia social y de las mentalidades, 10 (2006), pp. 24-25.

- Las estrategias de una elite frente a la tierra y al cielo: capellanías en Colchagua en el siglo XVII, en Gisela VON WOBESER, María MARTínEZ y Juan MuÑoz (coords.), Cofradías, capellanías y obras pías en la América colonial (Serie Historia Novohispana, 61), Universidad Nacional Autónoma de México, México, 1998, pp. 155-172.

- El convento de San Antonio en la doctrina de Malloa: Síndicos y Benefactores, siglo XVII y XVIII, en René MiLlar y Horacio ARÁNGUIZ DONOSO (eds.), Los franciscanos en Chile: Una bistoria de 450 años, Santiago de Chile, 2005, pp. 69-102.

OMAECHEVERRÍA, Ignacio, Escritos de Santa Clara y documentos complementarios, Madrid, 1993.

Palacios, Alfredo, Fuentes para la Historia sísmica de Chile (1570-1906), Santiago de Chile, 2016.

RAMÓn, Armando de y LARRAÍn, José, Una metrología colonial para Santiago de Chile: De la medida castellana al sistema métrico decimal, en Revista Historia, 14 (1979), pp. 5-69.

- Orígenes de la vida económica chilena: 1659-1808, Santiago de Chile, 1981.

REvUELTA, Manuel, La exclaustración (1833-1840), Madrid, 1976.

SAGREDO, Rafael, La expedición Malaspina en la frontera austral del imperio español, Santiago de Chile, 2004.

SANCHEZ GAETE, Marcial, La Capellanía camino de salvación, en Anuario de Historia de la Iglesia en Chile, 18 (2000), pp. 9-11.

- En las puertas del cielo, Clarisas capuchinas de Santiago de Chile: una fundación, 1727, en René MILLAR y Horacio ARÁNGUIZ DONOSO (eds.), Los franciscanos en Chile: Una historia de 450 años, Santiago de Chile, 2005, pp. 149-169.

San Francisco. Escritos \& Biografías. Documentos de la época, Madrid, 2007.

TRIVIÑO, Victoria, El libro que da forma a la vida claustral: la regla de Santa Clara, en los 800 años de la fundación de las clarisas, 1212-2012), en Francisco CAMPOS, La clausura femenina en el Mundo Hispánico: una fidelidad secular, El Escorial, 2011, pp. 425-448.

TROISI MELEAN, Jorge, Socios incómodos. Los franciscanos de Córdoba en una era de transformaciones (1767-1829), Rosario, 2016.

- Los franciscanos de la Provincia de Asunción en la transición del período borbónico y de las primeras décadas independientes, en Gardenia VIDAL y Pablo VAGLIENTE (comps.), Por la señal de la cruz. Estudios sobre la Iglesia Católica y sociedad en Córdoba, s. XVIII-XIX, Córdoba, 2006, pp. 115-132.

VON WOBEsER, Gisela, El Crédito Eclesiástico en la Nueva España, siglo XVIII, Universidad Autónoma de México, México, 1994.

- Vida eterna y preocupaciones terrenales. Las capellanías de misas en la Nueva España, 1700-1821, México, 1999.

— Dominación Colonial. La consolidación de vales reales, 1804-1812, México, 2003. 
